\title{
Constructing a Digital Academic Press Platform using Content Management System
}

\author{
Shun Wen Lin \\ Graduate student \\ Hsuan-Chuan University \\ Taiwan \\ Morgan Chang \\ Assistant Professor \\ Hsuan-Chuan University \\ Taiwan
}

\begin{abstract}
With the rapid development of internet applications, the patterns of academic press change obviously, therefore this research attempt to establish a academic publishing platform, which based on the content management systems (CMS), from a editor's point of view in practice. Through the flow and version control of the CMS, the capability and feasibility of the online editor team had been observed. Moreover, the conformity of information and the dissemination improvement also had been taken into account. We anticipate the technologies of content management lead-in the patterns of academic press can improve the editing process efficiency regarding to version control, change, save, publishing and information exchange.
\end{abstract}

The whole CMS system for online publishing had been implemented and two kinds of different academic press in Hsuan Chuang University, one print version and the other online version, had been choosen. The editing and publishing process had been evaluated. Finally, some results and suggestions had been provided.

\section{Introduction}

With the rapid development of new IT on the internet, the patterns of academic press had been changed from the traditional communication media, like publications and announcements, to e-mail, BBS and e-papers. The new type of publishing function was diverse from the traditional communication approaches, such as editing styles and circulating process ( Yu Wei Zhang, 1997). Based on this trend, the issue of publication management was more important than the user's visual impact on the press. Therefore, this research attempted to setup a publishing platform for academic press based on content management systems. This system developed by open source provided five kinds of different role for editing and reviewing the articles and other usable functions such as flow control and version control. We anticipated the technologies of content management lead-in the patterns of academic press could improve the editing process efficiency regarding to version control, change, save, publishing and information exchanges.

Content Management System (CMS) aims to assist company or person to management the contents and submit the message to people who needs (Chen Chi Chen, 2003). Content means all types of messages, including picture, text, image, audio and more. 
The management means that the processing of content control, such as collection, classification, access, approval, publication, update, delete, save and version control and so on (Boiko, 2002). On the other hand, in order to resolve the problems and requests of build, maintain or upload the website pages, the novel web technologies had been developed for the content management system (Digital Beijing, 2006).

The functionality of the library in the new era also needed to improve. Especially, the library role must be changed from an information collector to an information provider. Furthermore, the experiences accumulated and inspirations gained from publishing can be used in library promotion strategy and establishing a library new website easily (Coombs Karen A. , 2007). Librarians have been aware of the web contents potentially became rich and complex, which needed an powerful management tool to keep it updating correctly (Michael Seadle, 2005). Besides of the normal information disseminations of the library, the new interactive user environment of the website could encourage patrons to participate in knowledge sharing or to increase the attraction of readers by using multimedia (e.g. image, video, audio). On the other hand, the digital publishing was the tendency in the future. There are many information providers get into the publishing affairs. Therefore, we believe the academic library can be an information provider, even more be a content creator, as long as a user friendly publishing platform had been established. This research was based on content management system for campus press because of the user's requirements and the system functions were different. For the traditional press working flow which complicated and loose controlled, the modern digital press system keeps more interactions between author and editors and could be publishing on different media quickly.

\section{Methodology}

For increasing the extensibility of the CMS system, the open source software (Silva) had been taken into account to establish the whole publish system. Silva was developed by Infrae Inc. under GPL. This CMS system was based on Python language as scripting, Zope as web server, and defined XML structure as stored contents. According to the system design, the user role of Silva had been classified into five groups: "Author", "Editor", "Chief Editor", "Manager "and "Reader". Usually users could own multiple roles with different access rights assigned by Managers (see Table1, Table2). In order to achieve the best publishing workflow efficiency, this research tried to lead the traditional editing roles, i.e. author editor, to a virtual editing environment by access control. Figure 1 was shown the publishing workflow in the Content Management System. When the user logins, the system would let the user got to his/her homepage according to his /her role.

Table 1. The definition of role in Silva system

\begin{tabular}{|l|l|}
\hline Role & Definition \\
\hline Reader & The advance user. The user who only view the page which is public. \\
\hline Author & $\begin{array}{l}\text { The user who think content of page and submit publications to editors } \\
\text { approval. }\end{array}$ \\
\hline Editor & $\begin{array}{l}\text { The user who authenticating, proofreading and revising manuscripts and } \\
\text { submit publications for chief editor's approval. }\end{array}$ \\
\hline Chief Editor & $\begin{array}{l}\text { The user who has rights of assign new editors, authors, readers, viewers, set } \\
\text { up groups and submit for publication which is approved by editors. }\end{array}$ \\
\hline Manager & $\begin{array}{l}\text { The user who has rights as Chief Editor and has right to access systems } \\
\text { management area (e.g.templates). }\end{array}$ \\
\hline
\end{tabular}


Table 2. Roles within the Silva Environment

\begin{tabular}{|c|c|c|c|c|c|}
\hline Action & Reader & Author & Editor & $\begin{array}{l}\text { Chief } \\
\text { Editor }\end{array}$ & Manager \\
\hline $\begin{array}{l}\text { read, preview, } \\
\text { copy content }\end{array}$ & + & + & + & + & + \\
\hline $\begin{array}{l}\text { create, edit, delete, } \\
\text { unpublished content }\end{array}$ & & + & + & + & + \\
\hline submit for publication & & + & + & + & + \\
\hline $\begin{array}{c}\text { create editable version of } \\
\text { published content }\end{array}$ & & + & + & + & + \\
\hline approve, publish content & & & + & + & + \\
\hline define, change time frame & & & + & + & + \\
\hline $\begin{array}{l}\text { close, delete published content, } \\
\text { activate subscriptions, }\end{array}$ & & & + & + & + \\
\hline $\begin{array}{l}\text { assign new editors, authors, } \\
\text { readers, viewers, set up groups, } \\
\text { activate addable types of } \\
\text { content }\end{array}$ & & & & + & + \\
\hline $\begin{array}{l}\text { ZMI actions, add users, add } \\
\text { External Sources, refresh } \\
\text { content }\end{array}$ & & & & & + \\
\hline
\end{tabular}

Source: Silva 1.5 Documentation

(http://210.60.55.37:9080/AcademicPress/silva_docs/chief_editor/roles_permissions/) 


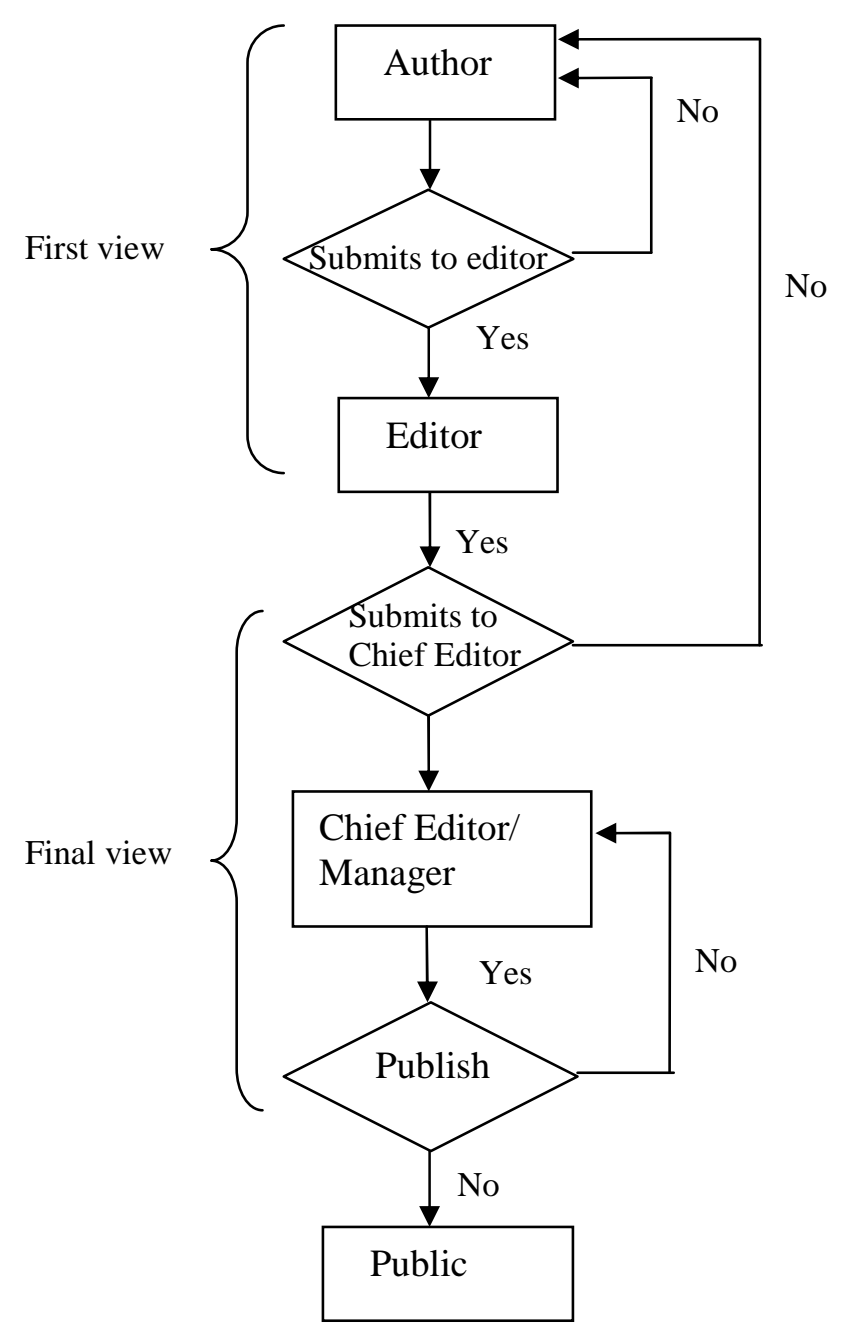

Figure 1. The publishing workflow in Content Management System

Figure 2 was shown the first step of the workflow of the publishing, where the author could create and revise his content. The metadata of the content was used as the 'metatags' (shown in Fiure 3), that was used by Internet search engines when indexing the website's pages. This step of adding metadata would be helpful for document management in the future. 


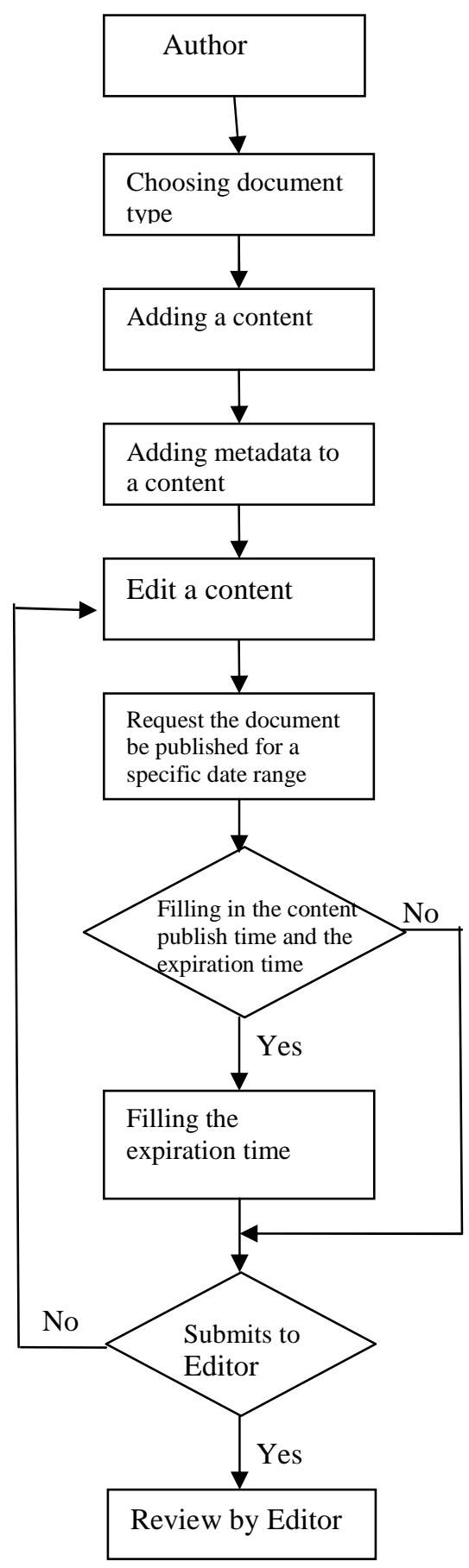

Figure 2. The Author's publishing workflow on editing a new content and submitting to 'Editor'. 


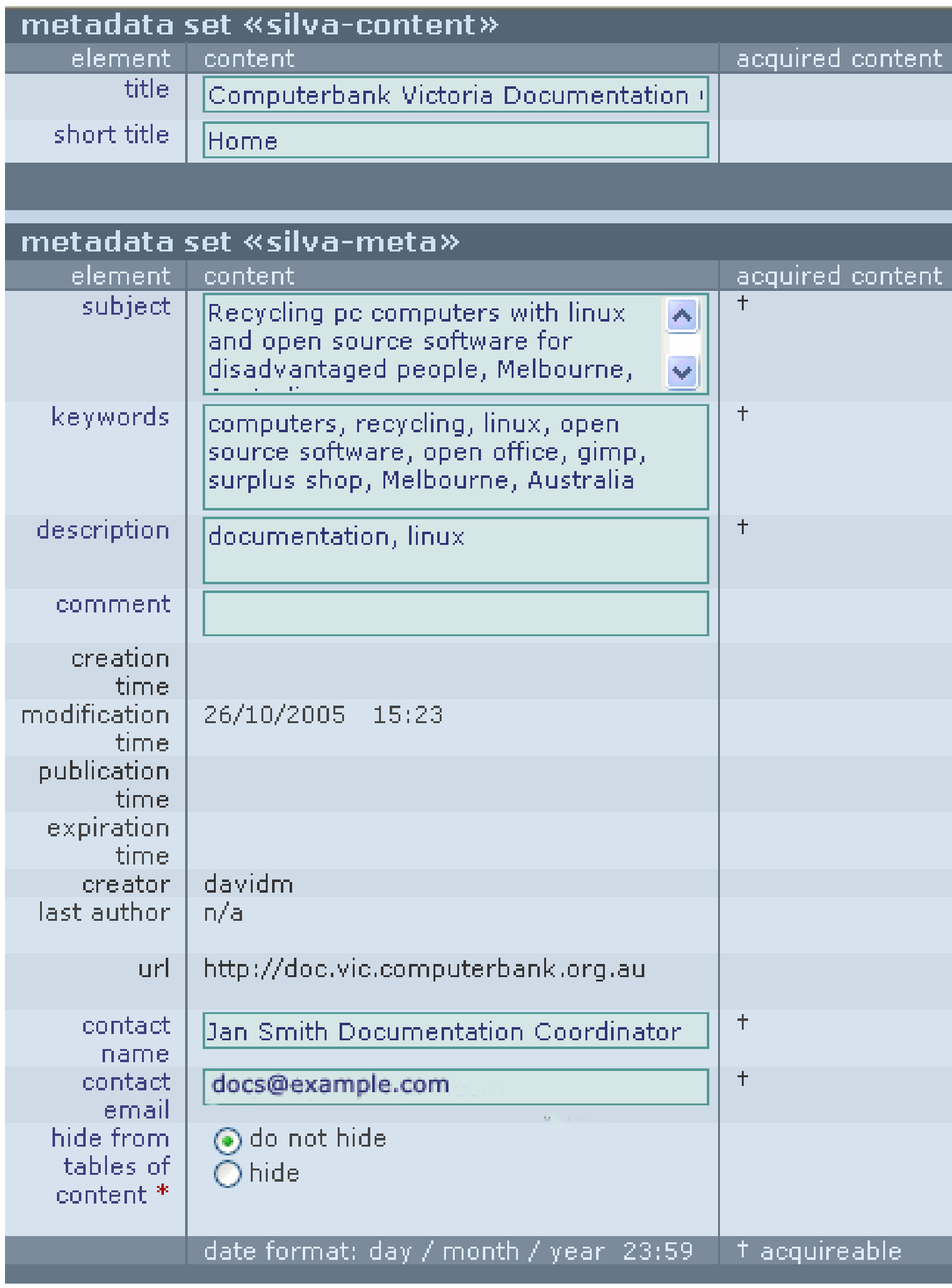

Figure 3. Metadata and properties

Figure 4 was shown the workflow of the content verification by the Editor. The screen shot was shown the properties tab on 'information page', which included author, title, keywords and description of content while the Editor viewing the content. That information could help the Editor review the content quickly. According to the Editor's review result, the manuscript will be rejected or submitted to the Chief Editor. Usually there were three 
different levels of authoring and rewriting chance before final publishing. The Editors was the gatekeeper before final manuscripts had been done (Gross, 1999).

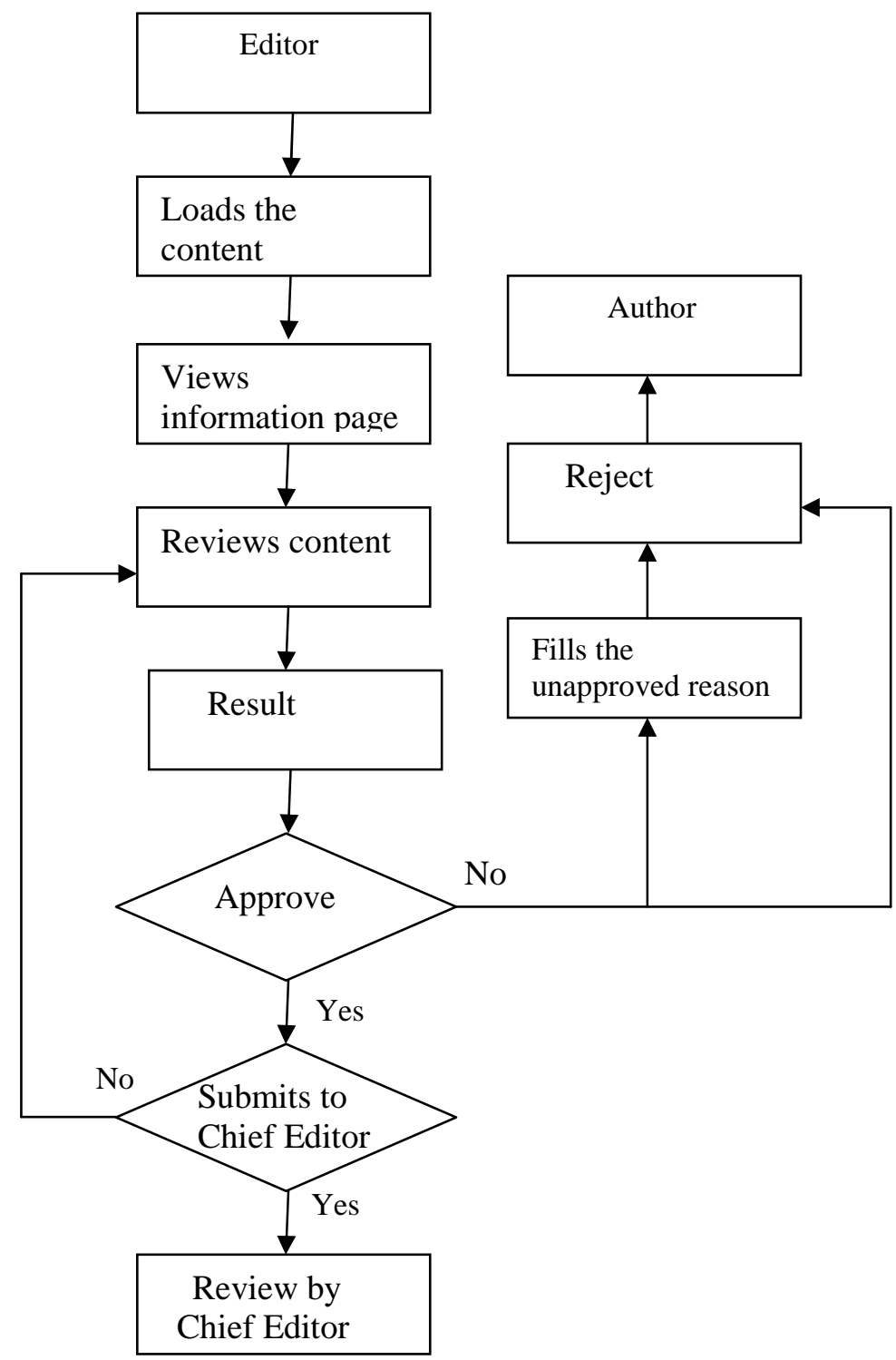

Figure 4. The workflow for Editor to approve content

Figure 5 was shown the last step of the publishing workflow, which the publication was approved by the 'Chief Editor' and the 'Manager'. Based on the role architecture, the Chief Editor and the Manager have the same right to review and to make decisions for publishing the contents submitted by the Editor. 


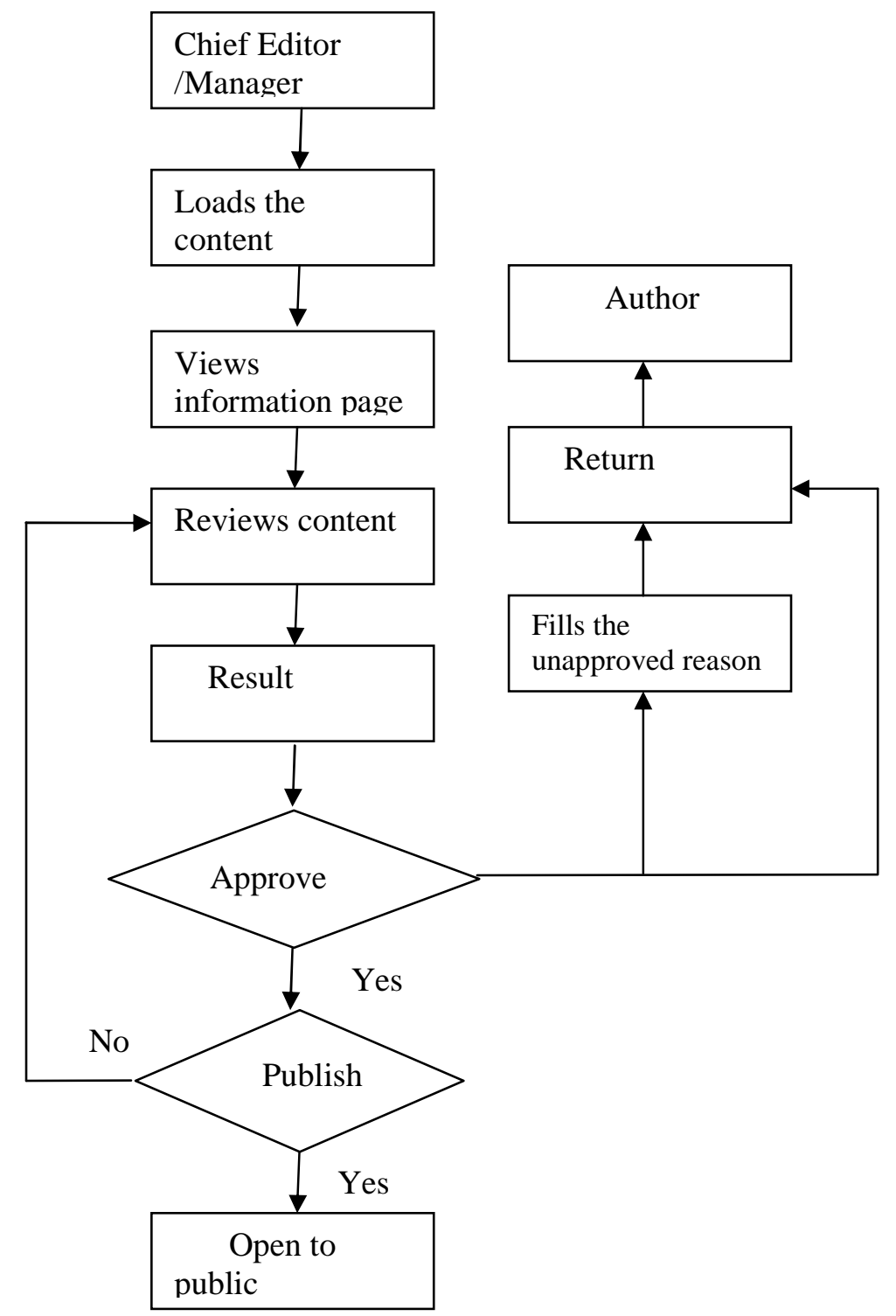

Figure 5. The publishing contents was approved by the Chief Editor and the Manager

\section{Results}

\section{Access right management}

Access right management (or access right control) was attempted to make the workflow of publishing more effectively and smoothly. By using several editing status and access right given properly, the documents could be controlled easily from written by journalists or contributors, to Editors, and Chief Editors. The status messages would reflect the progress and the access right of the document.

Access right management had advantages as follow: 
- The responsibilities between Author, Editor and Chief Editor roles was clear. The hierarchical role structure also had been provided different rights for each level, for example, the Editor could approve for publication, and the Chief Editor could create new Editors and Authors. There was no obscure within the workflow for the publishing.

- Besides the role for editing, a concept of group management had been introduced as shown in Figure 6. A virtual group could be created for the sake of member control like 'Writers'. Users allowed to join multiple groups.

- In order to better control the accessibility or the visibility of the content, the system provided roles such as Viewer, Viewer + and Viewer ++ to readers. Those different roles could be assigned to individual users or groups. Not only the editing process could be controlled, but the viewers for each document couled be fully managed.

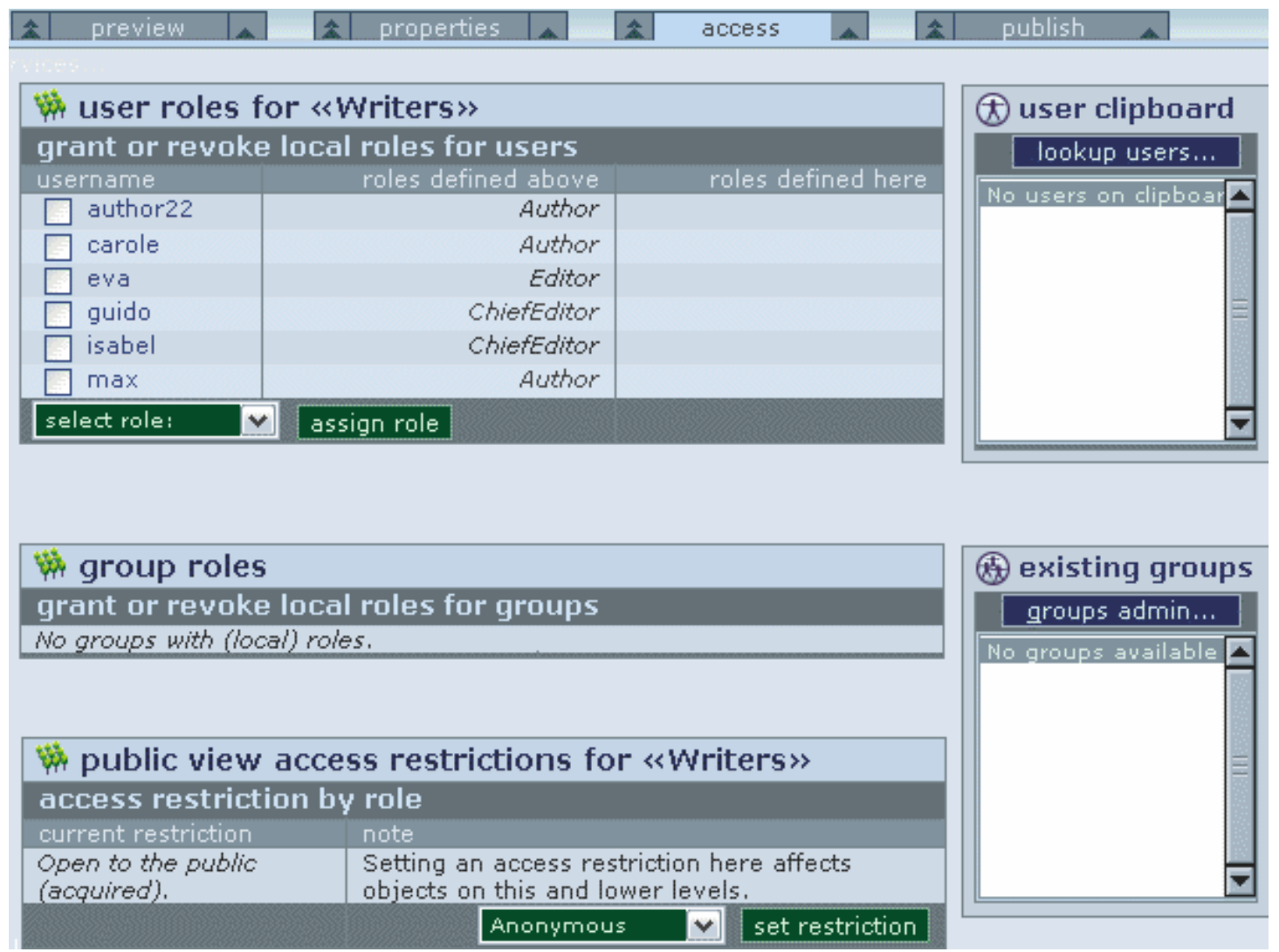

Figure 6. User role on managing area for a publication called Writers

\section{Document version control}

Version control could decrease the mistakes within the proofreading with different versions. As shown on Figure 7 and Table 3, the Silva system had been provided more functionalities on this process. By using the status messages, users could maintain the correct version for the publishing process and trace the ownship of each document of the publication. Figure 7 was shown the status of different versions of a publication. Users (editor or author) could review/compare all versions, even more to revert to an older version or to delete the publication. On the other hand, user also could choose any version of the publication as the initial content for a new version. 


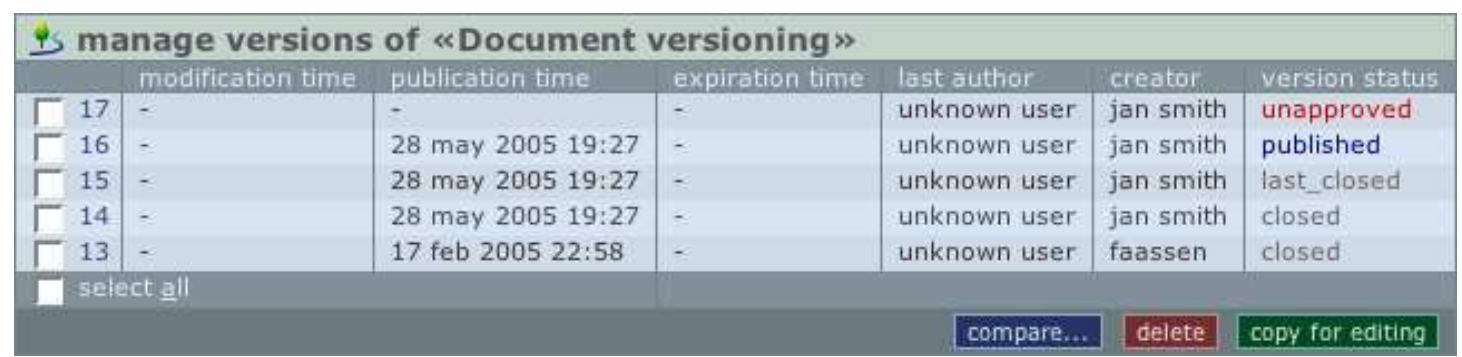

Figure 7. The screen shot of the version management

Table 3. The description of version status

\begin{tabular}{|l|l|}
\hline \multicolumn{1}{|c|}{ Version } & \multicolumn{1}{c|}{ Description } \\
\hline draft (red) & the version can be edited \\
\hline pending(yellow) & approval has been requested but has not yet been granted \\
\hline approved (green) & $\begin{array}{l}\text { a chief editor has approved the content but the publication date } \\
\text { hasn't passed yet }\end{array}$ \\
\hline published (blue) & the document is viewable by the public \\
\hline last_closed or closed (gray) & $\begin{array}{l}\text { the document is not in use anymore, where last_closed means } \\
\text { it's the most recent unused version }\end{array}$ \\
\hline
\end{tabular}

\section{Experimental publishing on academic press}

In order to explore the feasibility of the novel digital publishing system, we chose a biweekly journal (HCU BIWEEKLY ) as our study objective. This journal had only been published within Hsuan Chuang University. After the hardware and the Silva system had been established, a task force team had been organized which included the original reporters and editors for the journal. There are several steps to accomplish this study. a). Translating the Silva system into Traditional Chinese version. b). Organizing the task force team. c). Try to move all the workflow of editing into the system. d). Training the users to use the Silva system. e). Pilot publishing which parallel to the current journal's publishing. Furthermore, some factors such as online text editing tools, the working hours of editing and proofreading, and the total working hours for publishing, will be evaluated as indicators of the system performance.

The publishing system was in the pilot stage. Some working procedures and final publishing page had been shown on Figure 8 to Figure 11. 


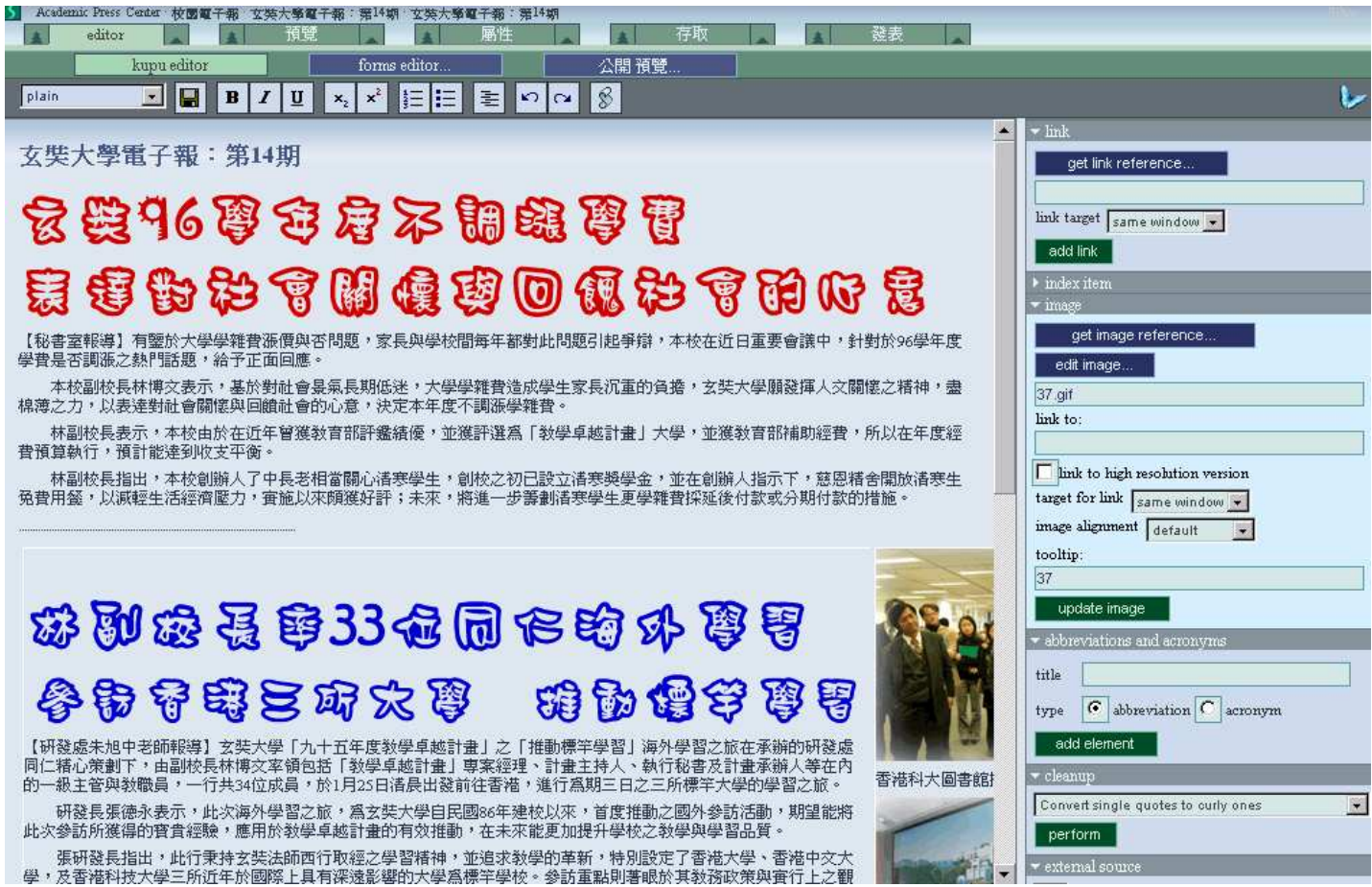

Figure 8. Kupu editor allows the authors to add text, links, images and more.

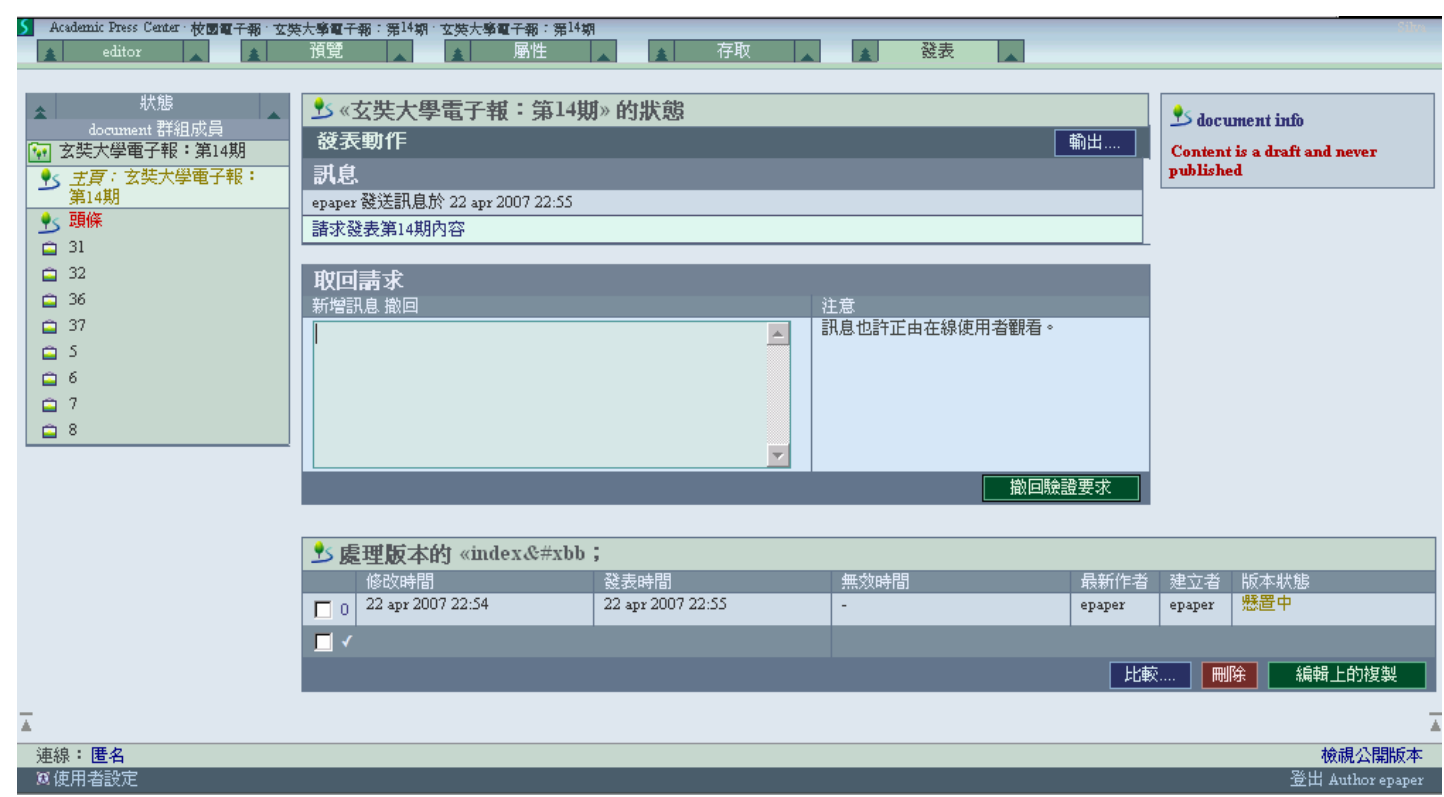

Figure 9. The screen shot of submitting publications for editor's approval.

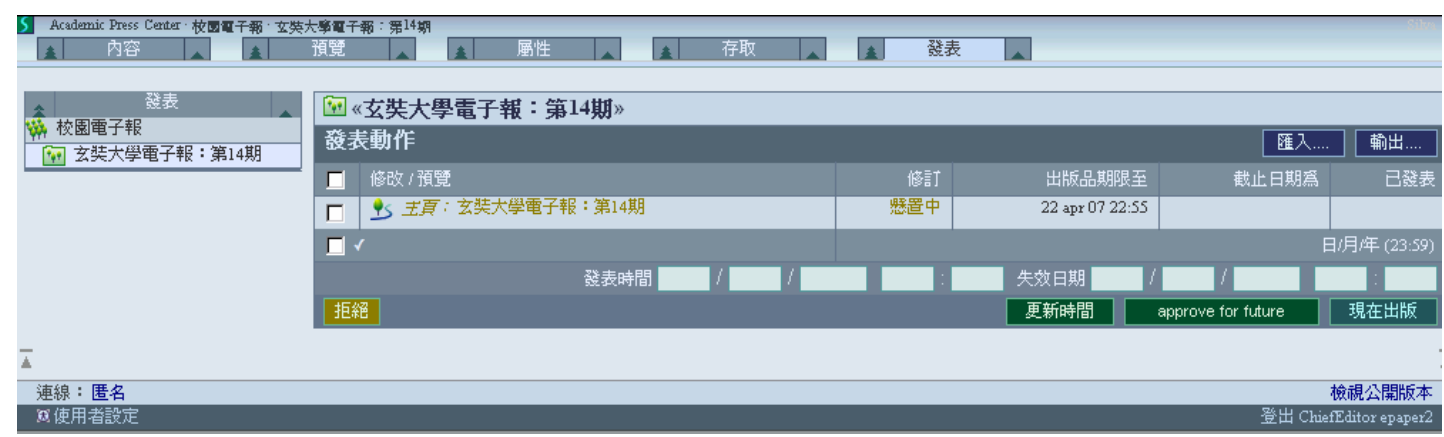

Figure 10. The screen shot of the publishing status. 


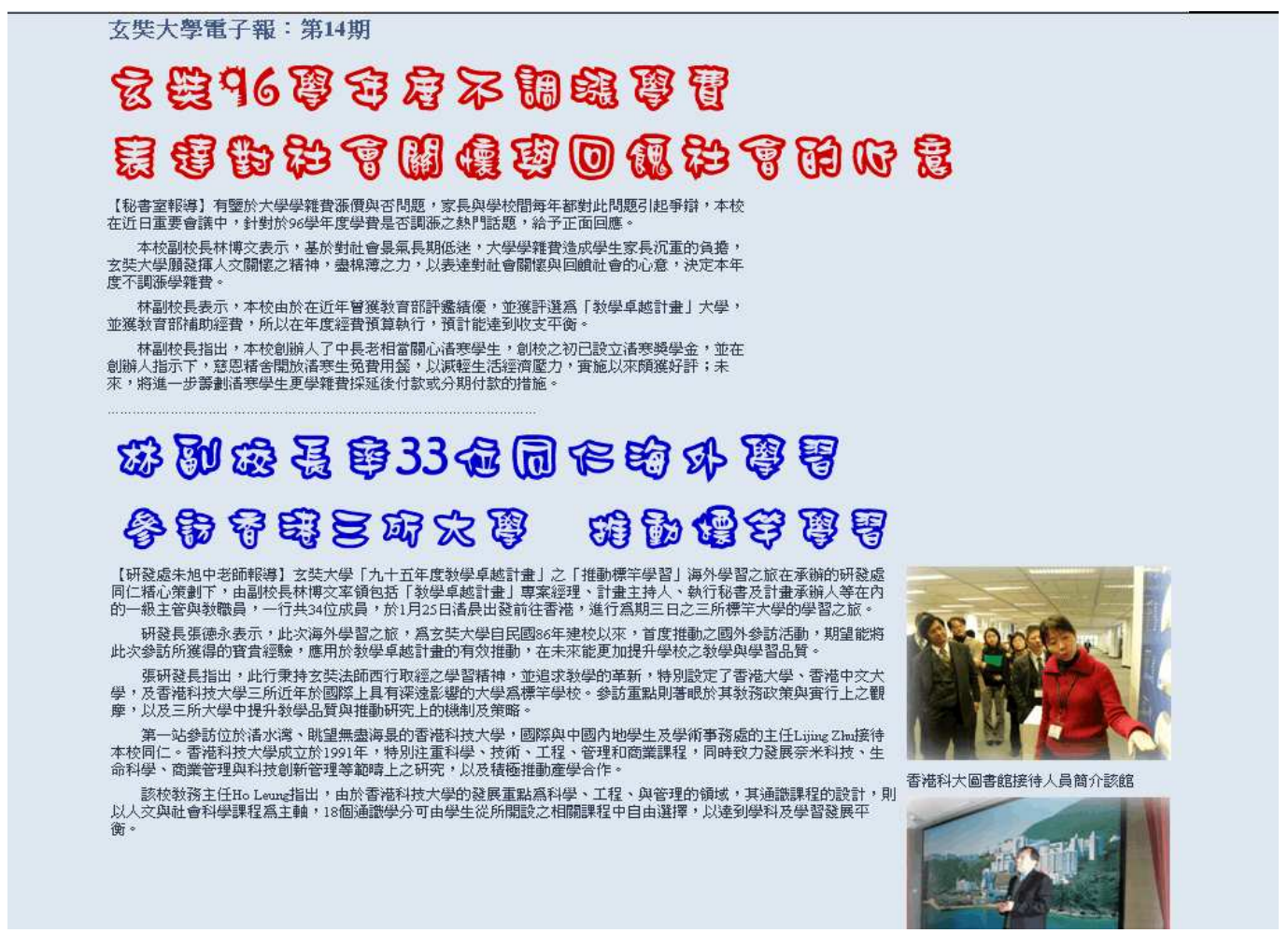

Figure 11. The screen shot of final public publication.

\section{Conclusions}

The search results had been revealed that the Silva could be satisfied the minimal requirements of the academic press. However, the limited functionalities of the editing tools became a big barrier for using CMS system. For example, the famous HTML editor like Adobe's Dreamweaver didn't provide any digital asset management function and workflow control function. Based on Silva system, a low-cost, short publishing cycle time, and total web-enable editing environment would be fully developed.

Finally, because of the limited time for surveying all the academic press, this study would focus on one current journal within Hsuan Chuang University; and we also tried to use document analysis method at the beginning of this study. When the task force team had been established, some indicators had been defined for evaluating the performance of the system. We anticipated this research results could provide more useful experiences and suggestions for other further studies on this issue.

\section{References}

Yu Wei Zhang(1997). The development and use of electronic newspapers. University Library Journal, 1(4). (in Chinese)

Chen Chi Chen(2003). An application of content management in FAQ. National Central University, Taiwan. (in Chinese)

Boiko, B.(2002). Content Management Bible. John Wiley \& Sons.

Digital Beijing(2006). What is Content management system? Retrieved May, 2006, from http://www.beijingit.gov.cn/ywyd/t20060526_127212.htm (in Chinese) 
Coombs,K.A. (2007). Building a Library Web Site on the Pillars of Web 2.0.Retrieved March 8, 2007, from http://www.infotoday.com/cilmag/jan07/Coombs.shtml

Michael Seadle(2005). EDITORIAL:Content management systems. 5 Library Hi Tech Vol. 24 No. 1, 2006 pp. 5-7.

Qiao Min Lin(2006).The times of library 2.0 is coming: about the e-paper affects the library. New Books:Recent Publications in Taiwan:90. (in Chinese)

Gross Gerald (1999).Editors on editing(Roch LanChi, Trans.).Taipei: COMMONWEALTH PUBLISHING CO. LTD. (in Chinese)

Silva, http://www.infrae.com/products/silva 